\title{
Motor Skills, Anthropometrical Characteristics and Functional Movement in Elite Young Soccer Players
}

\author{
Zalai $\mathrm{D}^{\mathbf{1} *}$, Bobak $\mathrm{P}^{2}$, Csáki $\mathrm{I}^{3}$, Hamar $\mathrm{P}^{4}$, Myrer JW' ${ }^{5}$, Mitchell $\mathrm{UH}^{5}$ and Johnson $\mathrm{AW}^{5}$ \\ ${ }^{1}$ Semmelweis University, Faculty of Physical Education and Sport Sciences, School of Ph.D. Studies, Budapest, Hungary \\ ${ }^{2}$ University of Leeds, Department of Orthopaedics, National Institute for Health Research, Leeds, UK \\ ${ }^{3}$ Semmelweis University, Faculty of Physical Education and Sport Science, Department of Physical Education Theory and Pedagogy, Budapest, Hungary \\ ${ }^{4}$ Semmelweis University, Faculty of Physical Education and Sport Science, Department of Gymnastics, Rhythmic Gymnastics, Dance and Aerobics, \\ Budapest, Hungary \\ ${ }^{5}$ Brigham Young University, Human Performance Research Center, UT, USA
}

Received: October 15, 2014; Accepted: January 08, 2015; Published: January 29, 2015

*Corresponding author: David Zalai, Faculty of Physical Education and Sport Science, Semmelweis University, Budapest, Hungary, Tel: 3630-3418712; E-mail: zalaidavid@yahoo.com

\begin{abstract}
This study examined functional movement patterns, anthropometrical characteristics and motor skills in elite young soccer players using the well-established Functional Movement Screen $^{\text {TM }}$ system $\left(\right.$ FMS $\left.^{\mathrm{TM}}\right)$. Sixty elite male soccer players participated (age $16.7 \pm 2.3 \mathrm{y}$, height $185.4 \pm 5.7 \mathrm{~cm}$, weight $82.8 \pm 6.7 \mathrm{~kg}$, BMI $24.1 \pm 1.3 \mathrm{~kg} / \mathrm{m}^{2}$ ) from four age-based teams. There were 7 Goalkeepers (GK), 17 Defenders (DEF), 27 Midfielders (MID) and 9 Forwards (FW). We measured $5 \mathrm{~m}, 10 \mathrm{~m}$, and $30 \mathrm{~m}$ sprint times and participants' vertical jump height and long jump distance. The FMS $^{\mathrm{TM}}$ was used to measure functional movement ability. Our study indicated that 5 of the 7 measured variables were significant when considering position assignment of advanced youth soccer players. These are the $5 \mathrm{~m}$ sprint, $30 \mathrm{~m}$ sprint, BMI, vertical jump, and FMS ${ }^{\mathrm{TM}}$ score. Functional movement ability may be useful in the physical development of soccer skills and performance. A FMS ${ }^{\text {TM }}$ score of $\leq 14$ was found in $28 \%$ of players and asymmetry was noted in $41 \%$, both considered an important risk factor of injury.
\end{abstract}

Keywords: Functional movement screen; Soccer performance; $30 \mathrm{~m}$ sprint; Movement patterns

\section{Introduction}

Soccer is among the most popular sports throughout the world [1]. Researchers have examined the motor skills of professional soccer players while few have investigated the motor skills of young non-professional players [1]. In soccer, motor skills are built upon aerobic and anaerobic capacity, speed, agility, and muscle strength[2]. Motor skills such as acceleration, deceleration, and the ability to change direction during maximal effort are crucial $[3,4]$, since soccer requires frequent and swift movements to evade opposing players and advance the ball during offensive and defensive play [5]. The optimization of these abilities results in high level soccer performance [6,7].

In the last decade, the physical requirements of soccer players in both senior and youth levels have increased enormously [2,8-10]. Game play requirements over the past few years have documented greater distances covered, higherintensity of activity and faster sprinting speeds. These physical demands of the game have necessitated improvements in general cardiovascular training [2] and also uncovered the need for improved training directed towards the specific physical skill components required to attain optimum performance [8-10]. This implies that an objective criterion beyond the opinion of experts is needed to help select optimal youth soccer players. Pre-screenings that assess functional movement quality, balance, speed, power and agility have become increasingly significant to reduce injury risk during play and predict performance [11-13].

A thorough assessment of potential soccer players should include evaluation of their physical characteristics, motor skills, functional movement ability in addition to their technical knowledge of the game, psychological profile or state, and experience level. The assessment of motor skills of soccer players is not new, as there is a significant relationship between skilled play and acceleration ability, maximum speed and running performance when changing directions $[14,15]$. Several studies have dealt with the anthropometrical characteristics and body composition of elite young players [8-10]. Players of different positions have different anthropometrical and physiological characteristics [16]. For example, a forward covers four times more distance at maximum speed (sprinting) than a defender will cover [17]. Compared to outfield players, goalkeepers are taller and weigh more, with longer arms, thighs and calves, and wider epicondyles on the humeri and femurs [13]. Due to the ever increasing physical requirements and differing demands of specific positions within the sport, not only sport-specific but also position-specific performance programs need to be defined and examined. Hughes et al. [18] has defined key factors of performance in the different positions: physiological, technical (defending and attacking) and psychological. These factors show the most significant differences when outfield players are compared to goalkeepers [18]. 
The Functional Movement Screen $\left(\right.$ FMS $^{\mathrm{TM}}$ ) attempts to assess the fundamental movement patterns of an individual $[19,20]$, which are learned during normal growth and development [21]. The FMS $^{\text {TM }}$ consists of seven movement patterns that require components of stability and mobility; it assesses trunk and core strength and stability, neuromuscular coordination, limb asymmetries during movement, postural control, proprioceptive deficits, and flexibility $[19,20]$. The FMS $^{\mathrm{TM}}$ movement patterns are: Deep Squat, Hurdle Step, In-Line Lunge, Shoulder Mobility, Active Straight Leg Raises, Trunk Stability Push-Up and Rotary Stability. The $\mathrm{FMS}^{\mathrm{TM}}$ is designed to assess the quality and efficiency of movement patterns, rather than the quantity of repetitions performed or the amount of weight lifted [19]. The FMS $^{\text {TM }}$ was originally designed as a screening tool for athletes to be able to identify compensatory movements that if consistently repeated could possibly lead to injury [19]. As such, the FMS ${ }^{\text {тM }}$ has been shown to effectively predict the likelihood of injury in professional athletes [22]. FMS ${ }^{\mathrm{TM}}$ scores $\leq 14$ out of 21 resulted in injury rates 11 times higher than scores over 15 [23]. Having an asymmetry, regardless of the total FMS $^{\mathrm{TM}}$ score doubled the risk of injury $[19,22]$. The FMS ${ }^{\text {TM }}$ was cited in a review study to effectively identify individuals who had a higher incidence of future injury in the populations studied [11]. FMS ${ }^{\text {TM }}$ outcomes have also been studied in military training [24], martial arts [25] and firefighters [26]. There is a growing emphasis on the importance of comprehensive movement preparation and sportspecific warm-up drills before practices and matches to minimize the risk of non-contact injuries

The purpose of this study was to compare the relationships between motor skills (speed [5 m, $10 \mathrm{~m}$ and $30 \mathrm{~m}$ sprints] and power [vertical and long jump]), anthropometrical characteristics (height, weight and BMI) and FMS $^{\mathrm{TM}}$ scores of elite young Hungarian soccer players according to player position and team. This information was further incorporated in a discriminant analysis to explore the predictive ability of these factors to predict player position. A tertiary aim was to determine the frequency of total $\mathrm{FMS}^{\mathrm{TM}}$ scores $\leq 14$ and of asymmetries in the $\mathrm{FMS}^{\mathrm{TM}}$ scores as these have been shown to indicate potential increased risk of injury in athletes.

\section{Materials and Methods}

\section{Participants}

Sixty male soccer players (age $16.7 \pm 2.3$ years, height 185.4 $\pm 5.7 \mathrm{~cm}$, weight $82.8 \pm 6.8 \mathrm{~kg}$, BMI $24.1 \pm 1.3 \mathrm{~kg} / \mathrm{m}^{2}$ ) participated in the study. These players were from four teams based on age, namely U16, U17, U18 and U19. There were 7 Goalkeepers (GK), 17 Defenders (DEF), 27 Midfielders (MID) and 9 Forwards (FW). Descriptive characteristics (age, height, weight and BMI) and soccer position of all participants are given in Table 1. Players were recruited from one of the Hungarian Soccer Academy programs; these players participated in yearlong soccer practice or match play. Typically, these athletes practice or have match play 5 days a week. Inclusion criteria require participants to be free of all extremity and spinal injuries for the past 6 months, and have not used performance-enhancing substances. A written informed consent document was obtained from each participant and/or legal guardian prior to any testing. All methods were approved by the university Institutional Review Board in accordance with the Helsinki Declaration. All study participants completed the study with no adverse side-effects and participated in all testing procedures.

\section{Procedures}

Participants in the study were asked to come to the testing after a full night of sleep, well hydrated, and having eaten earlier in the day. Testing occurred through the month of September and outdoors on a standard well maintained soccer field. Athletes completed a standardized, general warm-up of 10 minutes consisting of stretching and easy jogging. Participants did not engage in soccer practice or matches on the day of testing. Participants wore their standard uniform of socks, shorts and a T-shirt and wore standard soccer cleated shoes during the study. During anthropometrical measurements participants donned only their underclothing, without shoes, socks, shirts or shorts.

Participants' height was measured using a tape measure secured to a wall. Weight was assessed with a digital scale, calibrated with a known weight to ensure validity and reliability. After obtaining height and weight, we calculated the BMI as follows: $\mathrm{BMI}=$ mass $(\mathrm{kg}) /$ (height $\mathrm{x}$ height $)\left(\mathrm{m}^{2}\right)$. The same trained researcher conducted all anthropometrical measurements of the participants. Researchers reported the reliability of gathering weight and height measurements as excellent with Intraclass Correlation Coefficients (ICC) $\geq 0.96$ [27].

\section{Motor Skills}

Sprints: We tested the anaerobic performance of the players by measuring how fast they completed $5 \mathrm{~m}, 10 \mathrm{~m}$, and $30 \mathrm{~m}$ sprints from a standing position similar to Mendez-Villanueva et

Table 1: Anthropometrical variables of soccer players by position (mean \pm SD).

\begin{tabular}{|c|c|c|c|c|c|}
\hline & $\begin{array}{c}\text { TOTAL } \\
(n=60)\end{array}$ & $\begin{array}{c}\text { GK } \\
(n=7)\end{array}$ & $\begin{array}{c}\text { DEF } \\
(n=17)\end{array}$ & $\begin{array}{c}\text { MID } \\
(n=27)\end{array}$ & $\begin{array}{c}\text { FW } \\
(n=9)\end{array}$ \\
\hline Age (y) & $16.1 \pm 1.6$ & $15.8 \pm 1.6$ & $15.7 \pm 1.3$ & $16.5 \pm 0.8$ & $16.1 \pm 0.9$ \\
\hline Weight $(\mathrm{kg})^{*}$ & $73.8 \pm 7.9$ & $82.8 \pm 6.7^{*}$ & $74.7 \pm 9.7$ & $71.3 \pm 5.5$ & $72.8 \pm 6.4$ \\
\hline Height $(\mathrm{cm})^{*}$ & $180.2 \pm 6.5$ & $185.4 \pm 5.6^{*}$ & $182.5 \pm 7.5$ & $177.2 \pm 5.3$ & $181.1 \pm 4.6$ \\
\hline BMI $\left(\mathrm{kg} / \mathrm{m}^{2}\right) \dagger$ & $22.6 \pm 1.5$ & $24 \pm 1.2 \dagger$ & $22.3 \pm 1.6$ & $22.7 \pm 1.4$ & $22.1 \pm 1.2$ \\
\hline
\end{tabular}

GK: Goalkeepers; DEF: Defenders; MID: Midfielders; FW: Forwards

* Significant difference between player positions for height and weight $(\mathrm{F}=4.9$ and $\mathrm{F}=5.0, p=0.004)$.

† Significant difference between player positions $(\mathrm{F}=2.8, p<0.05)$. 
al. and Chamari et al. [28,29]. Infrared photocell (Matsport timing BTS, Seyssinet, France) timing lights were set at 4 points, these were the starting line and at $5 \mathrm{~m}, 10 \mathrm{~m}$, and $30 \mathrm{~m}$ from the starting line. Ample room for a safe slowdown was included beyond the finish line. The participants, on a visual cue, accelerated to full speed from a standing start position and ran through each of the photocells and the finish line. Athletes completed 3 trials with a 5 min rest between trials to ensure a full recovery between trials. The fastest of the three trials was used for analysis. Reliability of $10 \mathrm{~m}$ acceleration testing using timing lights has been reported as (ICC) $=0.92$ [30]. The reliability of the $30 \mathrm{~m}$ sprint test using infrared photocells was reported as ICCs of 0.97 to 0.99 [31].

4.3.2. Vertical jump from a static position: We tested the players' vertical jumping ability to assess power. The measurement of vertical jumping ability is the most common way to determine the explosive power of the lower limbs [32]. Each player attempted to jump as high as possible. Vertical jump height was measured using a measuring board (Taki and Company. Ltd., Japan). Each player performed three jumps with two minutes rest between jumps. The highest jump was selected for analysis. Reliability of the vertical jump has been reported as high $(r=0.93)[32,33]$.

Long jump from a static position: We measured the ability to long jump according to criteria reported by Almuzaini and Fleck [32]. The players performed a long jump from a standing position. Specific instructions were given to the players to begin the jump with flexed knees and arm swing was allowed to assist the jump. A starting line was marked and the length of the jump was determined using a tape measure affixed to the floor. Jumps were measured to the nearest $1 \mathrm{~cm}$ from the start line to the point where the heel closest to the starting line landed. If the player fell backward, the nearest body part from the start line to touch the ground was used to measure the distance of the jump. The best of three jumps was used for analysis. The reliability of this technique of measuring the long jump was found to be very high $($ ICC $=0.97)[32]$.

Functional Movement Screen: Players completed the 7 movement patterns of the FMS $^{\mathrm{TM}}$ according to established methods [19-21]. The 7 different movement patterns are: Deep Squat, Hurdle Step, In-Line Lunge, Shoulder Mobility, Active Straight Leg Raises, Trunk Stability Push-Up and Rotary Stability. The grading of the quality of the movement is based on specific objective criteria, and is expressed on a scale of 0 to 3.3 is given for movement performed correctly, without compensation; 2 is given for correct movement with compensation; 1 is given for an incorrect movement with compensation and 0 is given when pain occurs during the movement [19]. The highest score of three attempts is used for analysis. However, for those screen items that test right and left sides, and therefore assess symmetry (i.e., Hurdle Step, In-Line Lunge, Shoulder Mobility, Rotary Stability, and Active Straight Leg Raises), the lower score of the two sides for the screen item is used and the asymmetry was noted. The players can score a maximum of 21 points. The movements of the participants were assessed by a researcher trained in FMS ${ }^{\mathrm{TM}}$.
High [21] to good [34] inter-rater and moderate [34] intra-rater reliability in the adult population has been reported.

\section{Statistics}

We used the SPSS 21.0 Statistical Program (SPSS, Inc., Chicago, IL) to analyze data from our study. Differences between the soccer positions were determined by running a general linear model ANOVA (95\% confidence interval) with post hoc testing. Pearson-product correlation was used to examine the relationship between motor skills and $\mathrm{FMS}^{\mathrm{TM}}$. Discriminate analysis was used to distinguish which independent variables were predictors of group membership to the different soccer positions. A discriminate function was then created and tested to determine accuracy of the discriminate analysis. An alpha 0.05 was used for statistical significance. The results shown are mean and Standard Deviation (SD).

\section{Results}

There were statistically significant differences in anthropometrical measures between the player positions, see Table 1. Total participant and specific position means \pm SD of FMS $^{\text {TM }}$ scores, $5 \mathrm{~m}, 10 \mathrm{~m}$, and $30 \mathrm{~m}$ sprints, long jump and vertical jump are provided in Table 2. Significant differences were noted in defenders compared to other players in the $10 \mathrm{~m}$ and $30 \mathrm{~m}$ sprints, see Table 2 . Table 3 provides these variables grouped by age of participant (team), which did not show any statistically significant differences between groups. There were 28\%, 17 of the 60, players who scored a FMS ${ }^{\mathrm{TM}}$ score $\leq 14$ (1 goalkeeper, 3 defenders, 5 midfielders, 8 forwards) or (U15: 5 players (3 forwards, 1 defender, 1 midfielder); U16: 4 players ( 2 forwards and 2 midfielders); U17: 3 players (1 defender, 2 midfielders); U18: 5 players ( 1 goalkeeper, 1 defender and 3 forwards). We noted at least one or more asymmetries in $\mathrm{FMS}^{\mathrm{TM}}$ scores in $41 \%$ of participants.

There were expected significant correlations between height and weight $(\mathrm{r}=0.78)$, and weight and BMI $(\mathrm{r}=0.73)$. There were also significant positive correlations $(p \leq 0.05)$ between the tests of acceleration and speed ( 5 and $10 \mathrm{~m}$ sprint, $\mathrm{r}=0.8 ; 10$ and 30 $m$ sprints, $r=0.56)$. A significant correlation existed between the vertical jump and $30 \mathrm{~m}$ sprint $(\mathrm{r}=0.49)$ and vertical jump and long jump ( $r=0.55)$. There was however, no significant correlation between $\mathrm{FMS}^{\mathrm{TM}}$ and the anthropometric measurements $(p>0.05)$ (height, $r=-0.24$; weight, $r=-0.22$; BMI, $r=-0.10$ ) nor to the motor skills tests ( $5 \mathrm{~m}$ sprint, $\mathrm{r}=-0.14 ; 10 \mathrm{~m}$ sprint, $\mathrm{r}=-0.01$; $30 \mathrm{~m}$ sprint, $\mathrm{r}=0.04$; vertical jump, $\mathrm{r}=0.09$; long jump, $\mathrm{r}=0.04$ ). Defenders were significantly faster in the $10 \mathrm{~m}$ and $30 \mathrm{~m}$ sprints when compared to all other positions $(p<0.05)$.

Discriminate analysis indicated five significant variables to predict player positions; these are the 5 and $30 \mathrm{~m}$ sprints, BMI, vertical jump, total FMS ${ }^{\mathrm{TM}}$ score (Table 4). The $10 \mathrm{~m}$ sprint and long jump did not significantly predict player position. Classification results from discriminate analysis used to predict grouping of participants by soccer position (Table 5) showed a good predictability for goalkeepers with an $85.7 \%$ correct prediction, followed by $58.8 \%$ for defenders and fair predictability for forwards at $44.4 \%$. 
Table 2: Total FMS ${ }^{\mathrm{TM}}$ and motor skills scores by player position (Mean \pm SD).

\begin{tabular}{|c|c|c|c|c|c|c|}
\hline & $\begin{array}{c}\text { TOTAL } \\
(n=60)\end{array}$ & $\begin{array}{c}\text { GK } \\
(n=7)\end{array}$ & $\begin{array}{c}\text { DEF } \\
(n=17)\end{array}$ & $\begin{array}{c}\text { MID } \\
(n=27)\end{array}$ & $\begin{array}{c}\text { FW } \\
(n=9)\end{array}$ & $p$-value \\
\hline FMS $^{\mathrm{TM}}$ score & $15.47 \pm 1.93$ & $14.14 \pm 2.11$ & $15.72 \pm 1.99$ & $15.67 \pm 1.51$ & $15.44 \pm 2.65$ & 0.285 \\
\hline $5 \mathrm{~m}$ Sprint (s) & $1.10 \pm 0.06$ & $1.12 \pm 0.06$ & $1.07 \pm 0.06$ & $1.08 \pm 0.05$ & $1.12 \pm 0.07$ & 0.188 \\
\hline $10 \mathrm{~m}$ Sprint $(\mathrm{s})^{*}$ & $1.86 \pm 0.08$ & $1.91 \pm 0.04$ & $1.83 \pm 0.08$ & $1.85 \pm 0.07$ & $1.91 \pm 0.10$ & 0.027 \\
\hline $30 \mathrm{~m}$ Sprint $(\mathrm{s}) \dagger$ & $4.36 \pm 0.24$ & $4.54 \pm 0.12$ & $4.27 \pm 0.10$ & $4.36 \pm 0.12$ & $4.37 \pm 0.24$ & 0.001 \\
\hline Long jump (cm) & $226.2 \pm 14.4$ & $221.6 \pm 20.6$ & $230.4 \pm 13.1$ & $225.2 \pm 13.3$ & $224.9 \pm 15.2$ & 0.508 \\
\hline Vertical jump (cm) & $48.12 \pm 7.07$ & $46.13 \pm 7.91$ & $51.82 \pm 7.46$ & $47.15 \pm 6.30$ & $46.33 \pm 6.14$ & 0.069 \\
\hline
\end{tabular}

GK: Goalkeepers; DEF: Defenders; MID: Midfielders; FW: Forwards

* Significant difference between player positions $(\mathrm{F}=3.3, p=0.027)$

† Significant difference between player positions $(\mathrm{F}=6.1, p=0.001)$

Table 3: Descriptive parameters for $\mathrm{FMS}^{\mathrm{TM}}$, speed and jump tests between ages.

\begin{tabular}{|c|c|c|c|c|c|}
\hline & $\begin{array}{c}15 y \\
(n=14)\end{array}$ & $\begin{array}{c}16 y \\
(n=14)\end{array}$ & $\begin{array}{c}17 y \\
(n=16)\end{array}$ & $\begin{array}{c}18 y \\
(n=16)\end{array}$ & $p$-value \\
\hline FMS $^{\mathrm{TM}}$ score & $15.57 \pm 1.86$ & $15.21 \pm 2.42$ & $15.81 \pm 1.75$ & $15.25 \pm 1.81$ & 0.812 \\
\hline $5 \mathrm{~m}$ sprint $(\mathrm{s})$ & $1.10 \pm 0.07$ & $1.08 \pm 0.06$ & $1.11 \pm 0.07$ & $1.09 \pm 0.56$ & 0.675 \\
\hline $10 \mathrm{~m}$ sprint $(\mathrm{s})$ & $1.89 \pm 0.10$ & $1.85 \pm 0.07$ & $1.85 \pm 0.07$ & $1.86 \pm 0.07$ & 0.574 \\
\hline $30 \mathrm{~m}$ sprint $(\mathrm{s})$ & $4.43 \pm 0.20$ & $4.39 \pm 0.13$ & $4.30 \pm 0.15$ & $4.33 \pm 0.12$ & 0.119 \\
\hline Long jump (m)* & $2.14 \pm 0.12$ & $2.26 .07 \pm 0.15$ & $2.28 \pm 0.13$ & $2.34 \pm 0.11$ & 0.001 \\
\hline Vertical jump $(\mathrm{cm}) \dagger$ & $42.50 \pm 5.38$ & $44.86 \pm 5.31$ & $52.94 \pm 6.71$ & $51.06 \pm 5.34$ & 0.000 \\
\hline
\end{tabular}

* Significant difference between player positions $(\mathrm{F}=5.9, p=0.027)$

† Significant difference between player positions $(\mathrm{F}=11.1, p=0.001)$

Table 4: Significant variables from discriminant analysis.

\begin{tabular}{|c|c|c|}
\hline & Variable & P-value \\
\hline 1 & $30 \mathrm{~m}$ & 0.001 \\
\hline 2 & $5 \mathrm{~m}$ & 0.000 \\
\hline 3 & Vertical Jumping & 0.000 \\
\hline 4 & FMS $\mathrm{Tcore}$ & 0.000 \\
\hline 5 & BMI & 0.000 \\
\hline
\end{tabular}

Table 5: Classification results from discriminate analysis used to predict grouping of participants by soccer position.

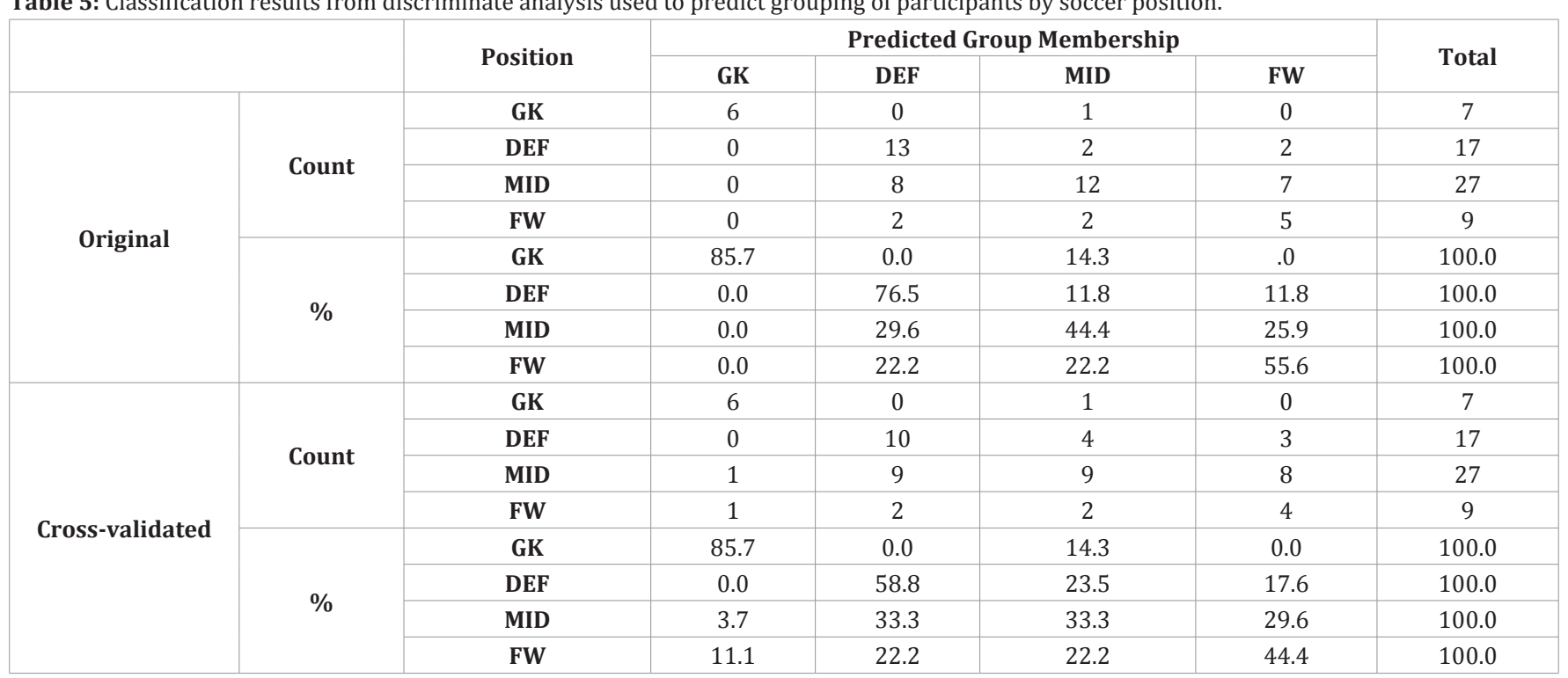

GK: Goalkeepers; DEF: Defenders; MID: Midfielders; FW: Forwards 


\section{Discussion}

The aim of this study was to find the relationships between motor skills, anthropometrical characteristics, and $\mathrm{FMS}^{\mathrm{TM}}$ scores, and then to use these factors to conduct a discriminate analysis to explore the predictive ability of these factors. There were the expected correlations between height, weight and BMI, while motor skills were also significantly correlated to each other. The FMS $^{\mathrm{TM}}$ was not correlated to motor skills or anthropometrical measures. We also examined if there were differences in motor skills, anthropometrical characteristics and FMS $^{\mathrm{TM}}$ scores regarding team (designated by age of participant) and soccer position. Our findings, though mostly not statistically significant, appear to be similar to those of other studies $[6,35,36]$. It is reported that elite soccer teams are characterized by a relative heterogeneity in body composition [6], which allows for specialization among the various soccer positions. Tall players would have advantages in certain aspects of play, such as goal keeping or defending. Even within a position, players of differing stature would likely utilize different tactics to be successful with their position; for example Reilly et al. [6] suggest that a tall forward may be used as a target for high balls, while a shorter forward may more likely run for balls played deep into the opponents' side of the field. This could possibly be true for other positions as well. There is also the possibility that a particular athlete who excels at a certain skill or due to superior athleticism can compensate for anthropometric disadvantages or lesser ability in another aspect of the sport $[37,38]$. Elite athletes have gone through several selection processes including their own inclinations toward the sport and performance within the sport. As athletes reach higher levels of play, it has been suggested by some researchers that it is not solely motor skills that make the difference in successful play, but it is also body structure and coordination [39]. This supports the idea of specialization within the various soccer positions. Thus, body dimensions, motor skills, and functional movement ability should have some predictive nature in the position selection of soccer players. Although this can be debated in our study population in whom some of these characteristics are still developing, it is possible that a player may perform well as a forward at 16 years old and then with future maturation, and skill/tactical development may be better suited as a midfielder by the time they are 18 years old. This might be especially true in midfielders who play a more defensive or offensive role within their position, based on the strategy of the coaches and needs of the team. This was supported in our discriminative analysis, as midfielders were the most difficult to predict in our analysis.

We analyzed the data from our participants to determine which of the measured variables were discriminative of the various positions in soccer. Our results indicated that 5 variables were useful in discriminating between positions, these were 5 and $30 \mathrm{~m}$ sprint times, vertical jump, BMI and $\mathrm{FMS}^{\mathrm{TM}}$ scores. These variables were then tested in a cross-validation for their usefulness in assigning membership within a certain soccer position grouping. This function best identified grouping of participants into goalkeepers and defenders. This is supportive of our findings of greatest degree of difference between these positions; goalkeepers were the tallest and heaviest, with the lowest FMS scores and vertical jump height, and had the slowest speeds in the $30 \mathrm{~m}$ sprint. Our discriminate function performed less well in those positions which soccer players tend to be more homogeneous in their body composition (i.e. mid-fielders and forwards). Some of the significant discriminant variables related to soccer position in our study have also been reported in other studies, such as running speed [14], jumping [32], and body dimensions [35]. It is interesting to note that the $\mathrm{FMS}^{\mathrm{TM}}$ score was one of the significant variables to predict position, despite its low correlation to the other variables. The FMS ${ }^{\mathrm{TM}}$ appears to be measuring an aspect of function, ability, or fitness that the other variables do not. If this is true, then the $\mathrm{FMS}^{\mathrm{TM}}$ may be valuable not only as a screening tool for potential injury risk as previously suggested [22], but also as a screening tool to predict the position of a soccer player.

We further assessed the frequency of total FMS $^{\mathrm{TM}}$ scores lower than 14 and the number of asymmetries in FMS $^{\mathrm{TM}}$ scores. The $\mathrm{FMS}^{\mathrm{TM}}$ has been suggested to help predict the risk of injury of an athlete during a competitive season [20,22]. Previous research suggests that athletes who score less than 14 have a 11 times increased injury risk [22]. We found that $28 \%$ of players in our study had FMS ${ }^{\mathrm{TM}}$ scores of $\leq 14$ [23]. Although none of the soccer position groups or team mean scores were under the critical 14 points, they also did not score above 16. It is important to consider an individual's scores when assessing injury risk in an effort to identify which player might be more susceptible to injury. It would also be important to determine if interventions designed to address identified areas of compromised movement, as identified by a low FMS $^{\mathrm{TM}}$ item score or asymmetry, would lead to a reduction in injury risk in soccer players. For instances, if a goal keeper scored low in the squat or lunge step or shoulder flexibility items, these being potentially important functional movements to a goal keeper, that player could engage in exercises or stretches to improve these items that may not be typically done in routine soccer practice or drills. These added exercise interventions may lead to an improved injury risk profile and perhaps even improved performance [20,22]. Our study found a relatively large number of forwards with lower FMS $^{\text {TM }}$ scores. The fact that $41 \%$ of the players had lower limb asymmetry is an important finding of this study as it represents a doubling of the risk factor of non-contact injuries and poor agility performance [40]. Perhaps, there should be an emphasis placed on symmetric functional movement ability in soccer players during soccer specific training [41]. This asymmetry and injury risk is suggested to be related to problems in proprioception and joint functional mobility and stability [19]. Some researchers have found intervention programs improving the quality of functional movement as represented by increases in $\mathrm{FMS}^{\mathrm{TM}}$ scores, and decreases in asymmetry and injury risk factors [23]. This improvement in functional movement would perhaps lead to more efficient athletic ability and superior performance [23].

The assessment and training of functional movement ability may be an important new aspect for the screening and development of future elite soccer players in addition to motor skills and anthropometrical characteristics. It has been 
suggested that significant increases in prevention and prehabilitation programs along with continuous screening of movement quality, may facilitate reducing injury and improving physical performance $[26,42]$. The ability to perform proper and symmetrical functional movements should become the foundation upon which the next levels of motor and sport-specific skills are built $[19,20]$.

There were certain limitations to our study. These include a relatively low sample size and the small number of players per position. A larger sample may have increased the likelihood of detecting differences among the dependent variables. Our study did however, point to possible relationships between the factors in our discriminate analysis and a possible prediction tool for position assignment. It was not an aim of the current study to determine the relationship between lower FMS $^{\text {TM }}$ scores and injury over an entire soccer season, although this would be valuable information to a player, coach, or physical therapist/ athletic trainer working with soccer players. Future prospective studies should follow players through practice and match play over the course of a season or a year to determine the $\mathrm{FMS}^{\mathrm{TM}}$ scores utility in assessing soccer players and various age and performance levels.

\section{Conclusion}

Recent studies indicate that the selection of talented soccer players is a long process and is done with thorough consideration of many factors [43]. Our study indicated that the $5 \mathrm{~m}$ sprint, 30 m sprint, BMI, vertical jump, and $\mathrm{FMS}^{\mathrm{TM}}$ score, were statistically significant in their capacity to correctly assign the current player position of advanced youth soccer players in a cross-validation. A lower $\mathrm{FMS}^{\mathrm{TM}}$ score in $28 \%$ of players and $41 \%$ asymmetries may suggest a practically significant injury risk in young soccer players.

\section{References}

1. Gil SM, Gil J, Ruiz F, Irazusta A, Irazusta J. Physiological and anthropometric characteristics of young soccer players according to their playing position: relevance for the selection process. J Strength Cond Res. 2007; 21(2): 438-45

2. Bangsbo J, Mohr M, Krustrup P. Physical and metabolic demands of training and match-play in the elite football player. J Sports Sci. 2006 24(7):665-74

3. Kutlu M, Yapıcı H, Yoncalık O, Çelik S. Comparison of a new test for agility and skill in soccer with other agility tests. J Hum Kinet. 2012; 33:143-50. doi: 10.2478/v10078-012-0053-1

4. Spinks CD, Murphy AJ, Spinks WL, Lockie RG. The effects of resisted sprint training on acceleration performance and kinematics in soccer, rugby union, and Australian football players. I Strength Cond Res. 2007; 21(1):77-85

5. Valente-Dos-Santos J, Coelho-E-Silva MJ, Severino V, Duarte J, Martins RS, Figueiredo AJ, et al. Longitudinal study of repeated sprint performance in youth soccer players of contrasting skeletal maturity status. J Sports Sci Med. 2012; 11(3):371-9.

6. Reilly T, Bangsbo J, Franks A. Anthropometric and physiological predispositions for elite soccer. J Sports Sci. 2000; 18(9):669-83.

7. Okada T, Huxel KC, Nesser TW. Relationship between core stability, functional movement, and performance. J Strength Cond Res. 2011; 25(1):252-61. doi: 10.1519/JSC.0b013e3181b22b3e.

8. le Gall F, Carling C, Williams M, Reilly T. Anthropometric and fitness characteristics of international, professional and amateur male graduate soccer players from an elite youth academy. J Sci Med Sport. 2010; 13(1):90-5. doi: 10.1519/JSC.0b013e3181b22b3e

9. Russel M, Tooley E. Anthropometric and performance characteristics of young male soccer players competing in the UK. Serb J Sports Sci. 2011; 5(4):155-62.

10. Vanttinen T, Blomqvist M, Hakkinen K. Development of body composition, hormone profile, physical fitness, general perceptual motor skills, soccer skills and on-the-ball performance in soccerspecific laboratory test among adolescent soccer players. J Sports Sci Med. 2010; 9(4):547-56.

11. Krumrei K, Flanagan M, Bruner J, Durall C. The accuracy of the functional movement screen to identify individuals with an elevated risk of musculoskeletal injury. J Sport Rehabil. 2014; 23(4):360-4. doi: 10.1123/jsr.2013-0027.

12. Kraus K, Schütz E, Taylor WR, Doyscher R. Efficacy of the functional movement screen: a review. J Strength Cond Res. 2014; 28(12):357184. doi: 10.1519/JSC.0000000000000556.

13. Hrysomallis C. Balance ability and athletic performance. Sports Med. 2011; 41(3):221-32. doi: 10.2165/11538560-000000000-00000.

14. Little T, Williams AG. Specificity of acceleration, maximum speed, and agility in professional soccer players. J Strength Cond Res. 2005; 19(1):76-8

15. Harris NK, Cronin JB, Hopkins WG, Hansen KT. Relationship between sprint times and the strength/power outputs of a machine squat jump. J Strength Cond Res. 2008; 22(3):691-8. doi: 10.1519/ JSC.0b013e31816d8d80.

16. Evaggelos M, Christos P, Konstantinos M, Ioannis G, Evaggelos B, Aristomenis $\mathrm{S}$. The effect of training, playing position, and duration of participation on aerobic capacity in soccer players. Journal of Physical Education and Sport 2012; 12(2):188-96.

17. Dellal A, Wong DP, Moalla W, Chamari K. Physical and technical activity of soccer players in the French First League - with special reference to their playing position. International SportMed Journal. 2010; 11(2):278-90.

18. Hughes MD, Bartlett RM. The use of performance indicators in performance analysis. J Sports Sci. 2002; 20(10):739-54.

19. Cook G, Burton L, Hoogenboom B. Pre-participation screening: the use of fundamental movements as an assessment of function - part 1 . N Am J Sports Phys Ther. 2006; 1(2):62-72.

20. Cook G, Burton L, Hoogenboom B. Pre-participation screening: the use of fundamental movements as an assessment of function - part 2 . N Am J Sports Phys Ther. 2006; 1(3):132-9.

21. Minick KI, Kiesel KB, Burton L, Taylor A, Plisky P, Butler RJ. Interrater reliability of the functional movement screen. J Strength Cond Res. 2010; 24(2):479-86. doi: 10.1519/JSC.0b013e3181c09c04.

22. Kiesel K, Plisky PJ, Voight ML. Can Serious Injury in Professional Football be Predicted by a Preseason Functional Movement Screen? N Am J Sports Phys Ther. 2007; 2(3):147-58.

23. Kiesel K, Plisky P, Butler R. Functional movement test scores improve following a standardized off-season intervention program in professional football players. Scand J Med Sci Sports. 2011; 21(2):28792. doi: 10.1111/j.1600-0838.2009.01038.x. 
24. O'Connor FG, Deuster PA, Davis J, Pappas CG, Knapik JJ. Functional Movement Screening: Predicting Injuries in Officer Candidates. Med Sci Sports Exerc. 2011. 43(12):2224-30. doi: 10.1249/ MSS.0b013e318223522d.

25. Bodden JG, Needham RA, Chockalingam N. The effect of an intervention program on functional movement screen test scores in mixed martial arts athletes. J Strength Cond Res. 2015;29(1):219-25. doi: 10.1519/ JSC.0b013e3182a480bf.

26. Peate WF, Bates G, Lunda K, Francis S, Bellamy K. Core strength: a new model for injury prediction and prevention. J Occup Med Toxicol. 2007; $2: 3$.

27. Berkson SS, Espinola J, Corso KA, Cabral H, McGowan R, Chomitz VR. Reliability of height and weight measurements collected by physical education teachers for a school-based body mass index surveillance and screening system. J Sch Health. 2013; 83(1):21-7. doi: 10.1111/j.1746-1561.2012.00743.x.

28. Mendez-Villanueva A, Buchheit M, Kuitunen S, Douglas A, Peltola E, Bourdon P. Age-related differences in acceleration, maximum running speed, and repeated-sprint performance in young soccer players. Sports Sci. 2011; 29(5):477-84. doi: 10.1080/02640414.2010.536248.

29. Chamari K, Hachana Y, Ahmed YB, Galy O, Sghaïer F, Chatard JC, et al Field and laboratory testing in young elite soccer players. Br J Sports Med. 2004; 38(2):191-6.

30. Duthie GM, Pyne DB, Ross AA, Livingstone SG, Hooper SL. The reliability of ten-meter sprint time using different starting techniques. J Strength Cond Res. 2006; 20(2):246-51.

31. Shalfawi SAI, Enoksen E, Tønnessen E, Ingebrigtsen J. Assessing TestRetest Reliability of the Portable Brower Speed Trap Ii Testing System. Kinesiology. 2012; 44(1):24-30.

32. Almuzaini KS, Fleck SJ. Modification of the standing long jump test enhances ability to predict anaerobic performance. J Strength Cond Res. 2008; 22(4):1265-72. doi: 10.1519/JSC.0b013e3181739838.

33. Beam WC, Adams GM. Exercise Physiology Laboratory Manual. 6th ed New York: McGraw-hill; 2010.
34. Teyhen DS, Shaffer SW, Lorenson CL, Halfpap JP, Donofry DF, Walker MJ, et al. The Functional Movement Screen: A Reliability Study. J Orthop Sports Phys Ther. 2012; 42(6):530-540. doi: 10.2519/ jospt.2012.3838.

35. Hencken C, White C. Anthropometric assessment of Premiership soccer players in relation to playing position. Eur J Sport Sci. 2006; 6(4):205-211.

36. Vaeyens R, Malina RM, Janssens M, Van Renterghem B, Bourgois J, Vrijens J, et al. A multidisciplinary selection model for youth soccer: the Ghent Youth Soccer Project. Br J Sports Med. 2006; 40(11):928-34.

37. Bartmus $U$, Neumann E, de Marees $\mathrm{H}$. The talent problem in sports. Int J Sports Med. 1987; 8(6):415-16.

38. Tranckle $\mathrm{P}$, Cushion C. Rethinking giftedness and talent in sport. Quest. 2006; 58(2):265-82.

39. Williams, A.M. and A. Franks, Talent identification in soccer. Sports Exercise and Injury, 1998. 4(4):159-65.

40. Jones PA, Bampouras TM. A comparison of isokinetic and functional methods of assessing bilateral strength imbalance. J Strength Cond Res. 2010; 24(6):1553-8. doi: 10.1519/JSC.0b013e3181dc4392.

41. Sedano CS, Vaeyens R, Philippaerts RM, Redondo JC, de Benito AM, Cuadrado G. Effects of lower-limb plyometric training on body composition, explosive strength, and kicking speed in female soccer players. J Strength Cond Res. 2009; 23(6):1714-22. doi: 10.1519/ JSC.0b013e3181b3f537.

42. Arnason A, Andersen TE, Holme I, Engebretsen L, Bahr R. Prevention of hamstring strains in elite soccer: an intervention study. Scand J Med Sci Sports. 2008; 18(1):40-8.

43. Lawrence I. Talent Identification in Soccer: A critical analysis of contemporary psychological research. Soccer Journal; 2010.55(1):24- 